\title{
Educational implementation programme of guidelines on cardiovascular risk factors: an analysis of changes in familiarity, use and attitudes
}

\author{
Risto Kuronen ${ }^{1}$, Piia Jallinoja ${ }^{2}$, Riitta Airola ${ }^{3}$ and Kristiina Patja ${ }^{4}$ \\ ${ }^{1}$ Medical Advisor, Joint Authority for Päijät-Häme Social and Health Care, Sykekatu, Lahti, Finland \\ ${ }^{2}$ Head of Unit, Senior Researcher, The National Institute for Health and Welfare, Finland \\ ${ }^{3}$ Senior Lecturer in Nursing, Lahti University of Applied Sciences, Finland \\ ${ }^{4}$ Adjunct Professor, Director, The National Institute for Health and Welfare, Finland and The Association \\ for Medical Continuous Professional Development in Finland (Pro Medico), Finland
}

\begin{abstract}
Aim: To explore changes in self-reported familiarity and use of guidelines dealing with cardiovascular risks (hypertension, dyslipidemia, adult obesity and smoking cessation) and general attitudes towards clinical guidelines before and after implementation programme, as well as the association of guideline training attendance and attitudes towards and use of guidelines. Background: The current care guidelines provide a useful tool in the management of cardiovascular risk factors. Evidence-based care and guideline use have a shorter tradition among nurses than among physicians. Methods: A self-administered questionnaire was sent to all primary health care nurses and physicians in Päijät-Häme Health and Social Care District, an area of 210000 inhabitants in Southern Finland, before and after the guideline implementation programme VALTIT. Findings: Main outcome measures were self-reported familiarity with and use of guidelines on cardiovascular risks and items measuring attitudes towards clinical guidelines.

Among nurses, the reported familiarity with all the guidelines increased, but increase in use occurred only in respect of the dyslipidemia guideline. Among nurses, there was an association between participation in guideline training and guideline use. Physicians' reported familiarity with and use of the adult obesity guideline increased during the study period. The proportion of nurses and physicians who reported that they had been asked to use the guidelines increased. Perceptions concerning the readiness to adopt the guidelines changed positively among nurses and were more positive among those attending at least one training event.

Results are encouraging regarding familiarity with guidelines. Regarding usage our results suggest that a two-year programme might not be enough to alter the deep-rooted practices and attitudes concerning lifestyle change related guidelines. The challenge lies in multi-professional implementation of guidelines on cardiovascular risks with special emphasis on lifestyle change as a treatment option.
\end{abstract}

Key words: cardiovascular; guideline; health care personnel; implementation Received 13 July 2009; accepted 13 December 2009; first published online 14 May 2010

Correspondence to: Risto Kuronen, Joint Authority for PäijätHäme Social and Health Care, Sykekatu 8 B 34, 15850 Lahti, Finland. Email: risto.kuronen@fimnet.fi

(C) Cambridge University Press 2010 


\section{Background}

Evidence-based clinical guidelines have become a key source of data in organising practices in health care (Grol and Buchan, 2006). The aim of the guidelines is to raise the quality of health care and remove variations in practices. The real challenge lies in creating changes in health care professionals' behaviour and practices (Oxman et al., 1995).

In Finland, current care guidelines have been published since 1994 by the Finnish Medical Society Duodecim. Most are targeted at medical treatment. The guidelines can be freely accessed in the Internet (www.kaypahoito.fi) and the vast majority of health professionals have access to the Internet at their workplace. Although availability is good, the implementation of the guidelines is not systematic: methods vary markedly between health centres (Miilunpalo et al., 2001; Alanen et al., 2007).

Lifestyle-related diseases form a major challenge for primary health care in Finland (Peltonen et al., 2006). Preventive measures are needed and the current care guidelines provide a tool in the enhancement of management of cardiovascular risk factors. Currently, physicians use guidelines in clinical decision making when treating diseases but less when considering primary preventive actions (Mazza and Russell, 2001).

We have shown in our previous study that health care professionals find the clinical guidelines in general reliable and trust that guidelines are evidence based and developed by experts (Kuronen et al., 2006). As expected, nurses were less familiar with the guidelines related to cardiovascular risks than physicians. In Finland, however, primary health care nurses form a major professional group responsible for the lifestyle counseling in health care, although the management of cardiovascular risk factors is a multidisciplinary task. Although primary prevention is among major tasks within healthcare, it often falls behind treatment of diseases as healthcare organisations rarely set targets for effects or use incentives.

This study is a part of an implementation programme of current care guidelines on cardiovascular risks factors. The programme targeted both physicians and nurses. Hence, it provides valuable information on nurses, too, that have previously been ill-studied in respect of guidelines implementation (Thomas et al., 2000; Grimshaw et al., 2004; Thompson et al., 2007).
The study questions were: 1) did familiarity with and use of the guidelines increase during the programme, 2) did attitudes towards guidelines change and 3) was the participation in guideline training associated with guideline use and attitudes towards guidelines.

\section{Methods}

This study reports the results of the Current Care Guidelines Implementation Programme (VALTIT), which was a part of the GOAL research and development project (Good Aging in Lahti Region) (Fogelholm et al., 2006). VALTIT-programme was conducted between spring 2006 and autumn 2007 in Päijät-Häme Health and Social Care District. The biggest town in the region is Lahti (100000 inhabitants). The programme was targeted at nurses, public health nurses and physicians in primary care and the health care personnel in secondary care treating metabolic syndrome and its consequences. The programme is described in Table 1 . The training was marketed using emails to chief physicians and nurses, through the programme workgroup and in the programme regional extranet. Participation in the lectures and workshops was voluntary.

The VALTIT programme was evaluated by a questionnaire study conducted before and after the programme. The baseline questionnaire was sent between October 2004 and January 2005 and the second questionnaire after the first round of intervention between November 2006 and January 2007. The questionnaires had two paper reminders. The second reminder on the latter round was sent as an e-mail to the physicians suggesting filling in the electronic questionnaire in the Internet.

The questionnaires were sent to all primary care physicians and nurses of the hospital district according to the lists provided for the research team by the chief nurses and head physicians of health centres and to physicians and nurses working with metabolic syndrome in central hospital. With regard to the nurses in primary care in Lahti, some units were not included in both rounds. For the purposes of this comparative study, we have included only nurses in the units included in both rounds. The present paper reports the results for primary care professionals, because the prevention of cardiovascular risks is a 
Table 1 The components used in the Current Care Guidelines Implementation Programme (VALTIT)

Engaging the health centres

- assembling the working group with nurses and physicians from primary and secondary care, nutrition specialist and teachers in nursing

- representatives of the project visited all the health centres in spring and summer 2005 and marketed the programme

- distribution of all reports and diaries of the project to the chief physicians and head nurses

The local clinical guidelines tool

- developed by a multi-professional group with representatives from the hospital district, municipalities and Public Health Institute

- included local chains of care in hypertension, dyslipidemia, adult obesity and tobacco dependency based on national guidelines and suggestion for division of work in lifestyle counselling

- collected previously documented good practices of primary prevention from the region to be included in the set of tools

- published on the extranet for the region's health professionals

Training the health professionals

- in spring 2006 five centralised training sessions (based on national guidelines if available, invitations via email to all health centres) were arranged: hypertension and adult obesity, dyslipidemia, type 2 diabetes, tobacco dependency, health counseling and communication

- interactive workshops with case method learning (Kiessling and Henriksson, 2002) were arranged in spring 2006 in 5 of 15 health centres. The cases were hypertension + dyslipidemia and type 2 diabetes + obesity

more central part of their daily tasks than it is among secondary care professionals.

The questionnaires covered attitudes towards, familiarity with and use of the current care guidelines in general and specially the guidelines on cardiovascular risks, which were used in year 2004 (hypertension, dyslipidemia, adult obesity and smoking cessation) (Kuronen et al., 2006), as well as current practices in and attitudes towards lifestyle counseling (Jallinoja et al., 2006; 2007). These separate guidelines were chosen because there is no guideline targeting specifically cardiovascular prevention in Finland. The questionnaire was piloted among participants attending a quality course on type 2 diabetes targeted at health care personnel of the health and social care district.

The present paper applies questions related to clinical guidelines in general and the four published national guidelines related to cardiovascular risks: the guidelines on dyslipidemia, high blood pressure, adult obesity and smoking cessation. We measured the reported familiarity with these guidelines, participation in individual guideline training and use of these guidelines. Familiarity was measured with the statements 'I have read the guideline carefully',I have got acquainted with the guideline', I have browsed the guideline', 'I have heard the guideline' and'I don't know the guideline'. Options were agree or do not agree. In this paper we combine the first three to 'I have read or browsed the guideline'. Participation in training was measured with the statement 'I have participated in the training related to this guideline' (agree, do not agree) and use of the guideline with statement 'I have used the guideline during six months' (agree, do not agree). To the statement 'I have been recommended at work to use the guideline' answering options were also agree or do not agree. Regarding the general attitudes to the guidelines and the readiness to adopt the guidelines, we analysed the following items: 'My occupational competence is insufficient for adopting the latest guidelines' and 'Guidelines are hard to find' which are part of the Attitudes towards Guidelines Scale (Elovainio et al., 1999) and 'The guidelines are too complicated' which was included only in the second questionnaire. These statements were assessed with five-point Likert scale and answering options was 'totally agree', 'partially agree', 'in between', 'partially disagree' and 'totally disagree'.

Fifty-nine primary care physicians and 136 nurses returned a completed questionnaire in the first round and 58 physicians and 127 nurses returned one in the second round. The response rate in primary care was $59 \%$ (physicians $53 \%$, nurses $62 \%$ ) in the first round and $57 \%$ (physicians $48 \%$, nurses $59 \%$ ) in the second. The demographics of the respondents are presented in Table 2. Nurses in Finnish primary care work mainly with physicians as a pair assisting them and perform minor medical procedures. Public health nurses mainly work in child, in maternity and school care and in occupational health. Public health nurses' education is one year higher than nurses and with more focus in public health.

The distributions before and after were examined in cross tabs and statistical testing with $\chi^{2}$ test with SPSS version 15 . Individual before and after testing was not possible because participants in questionnaires were not necessarily the same. 
Table 2 Background characteristics of the respondents in primary care, years 2004, 2006

\begin{tabular}{|c|c|c|c|c|}
\hline & \multicolumn{2}{|l|}{ Physicians (\%) } & \multicolumn{2}{|l|}{ Nurses (\%) } \\
\hline & $2004(n=59)$ & $2006(n=58)$ & $2004(n=136)$ & $2006(n=127)$ \\
\hline \multicolumn{5}{|l|}{ Gender } \\
\hline Male & 52 & 46 & 1 & 1 \\
\hline Female & 48 & 54 & 99 & 99 \\
\hline \multicolumn{5}{|l|}{ Age } \\
\hline Under 40 years & 22 & 26 & 30 & 34 \\
\hline $41-54$ years & 52 & 51 & 51 & 44 \\
\hline Over 54 years & 26 & 24 & 18 & 22 \\
\hline \multicolumn{5}{|l|}{ Education } \\
\hline Specialist (any speciality) & 46 & 49 & & \\
\hline Non-specialist & 54 & 51 & & \\
\hline Public health nurse & & & 57 & 38 \\
\hline Nurse & & & 30 & 46 \\
\hline Public health nurse and nurse & & & 7 & 9 \\
\hline Some other health care education & & & 6 & 8 \\
\hline
\end{tabular}

Table 3 Familiarity with and use of the guidelines

\begin{tabular}{|c|c|c|c|c|c|c|}
\hline & \multicolumn{3}{|l|}{ Nurses } & \multicolumn{3}{|l|}{ Physicians } \\
\hline & $2004(n=136)$ & $2006(n=127)$ & $P$-value & $2004(n=59)$ & $2006(n=58)$ & $P$-value \\
\hline \multicolumn{7}{|c|}{ Have read or browsed the guideline } \\
\hline Dyslipidemia & 43 & 68 & 0.001 & 90 & 93 & 0.509 \\
\hline Adult obesity & 49 & 65 & 0.007 & 60 & 76 & 0.064 \\
\hline Tobacco & 33 & 49 & 0.007 & 63 & 67 & 0.608 \\
\hline \multicolumn{7}{|c|}{ Have used the guideline } \\
\hline Hypertension & 34 & 46 & 0.052 & 58 & 68 & 0.226 \\
\hline Dyslipidemia & 13 & 22 & 0.034 & 54 & 63 & 0.313 \\
\hline Adult obesity & 19 & 24 & 0.337 & 19 & 38 & 0.017 \\
\hline Tobacco & 9 & 10 & 0.828 & 31 & 23 & 0.377 \\
\hline \multicolumn{7}{|c|}{ Have been recommended to use the guideline } \\
\hline Hypertension & 35 & 44 & 0.151 & 25 & 43 & 0.040 \\
\hline Dyslipidemia & 9 & 18 & 0.035 & 12 & 28 & 0.025 \\
\hline Adult obesity & 10 & 19 & 0.026 & 5 & 13 & 0.120 \\
\hline Tobacco & 7 & 10 & 0.272 & 3 & 10 & 0.150 \\
\hline
\end{tabular}

Proportion (\%) of those nurses and physicians in 2004 and 2006 who reported that they have read or browsed the guideline, have used the guideline during the last six months and have been recommended at work to use the guideline.

The research plan for the questionnaire study was approved by The Institutional Review Board of the National Public Health Institute, Finland.

\section{Results}

\section{Familiarity with the guidelines}

In 2004, almost all of the physicians reported having read or browsed the hypertension and dys- lipidemia guidelines and two-thirds had read or browsed the adult obesity and smoking cessation guidelines (Table 3 ). Four out of five nurses reported that they have read or browsed the hypertension guideline in 2004 (Table 3). The proportion of those nurses who reported have read or browsed the guideline increased during the study period with regard to all the guidelines. There was no statistically significant change in familiarity with the guidelines among the physicians during the study period. 


\section{Use of the guidelines}

Before the programme, over half of the physicians reported that they have used the hypertension and dyslipidemia guidelines during the past six months (Table 3). The increase in reported use among physicians occurred in the adult obesity guideline and among the nurses in the dyslipidemia guideline. There was a significant increase in the proportion of nurses and physicians reporting that they have been recommended to use a certain guideline (Table 3).

\section{The association of participation in VALTIT training in use and attitudes}

In $2006,34 \%$ of the primary care nurses reported that they had participated in at least one centralised training session of VALTIT programme and 17\% reported have participated in a local workshop of the VALTIT project. In total, 39\% of nurses had participated in at least one training event. The corresponding proportions among physicians were $31 \%$ for centralised training, $15 \%$ for local workshops and 36\% in some VALTIT training event.

As the number of physicians in the second round of the questionnaire was rather small, we could not analyse the association between the physicians' participation in VALTIT training sessions and the use of and attitudes towards the guidelines.
Among nurses, there was an association between the use of the guidelines on dyslipidemia, obesity and smoking cessation and participation in VALTIT training (Figure 1). Moreover, perceptions concerning readiness to adopt the guidelines were more positive among those nurses who had taken part in at least one VALTIT training event (Table 4).

\section{Attitudes towards guidelines}

The number of those nurses who agreed with the statement 'My occupational competence is insufficient for adopting the latest guidelines' decreased during the study period from $11 \%$ to $2 \%(P=0.016)$, while among physicians there was no statistically significant change $(5 \%$ versus $9 \%, P=0.470)$. In the case of the statement 'Guidelines are hard to find' there was no statistically significant change among the nurses $(29 \%$ versus $24 \%, P=0.135$ ) or among the physicians ( $32 \%$ versus $16 \%, P=0.132$ ).

\section{Discussion}

The guidelines studied here can be divided into two groups by the task definition of the guideline. First, medication-oriented guidelines, the hypertension

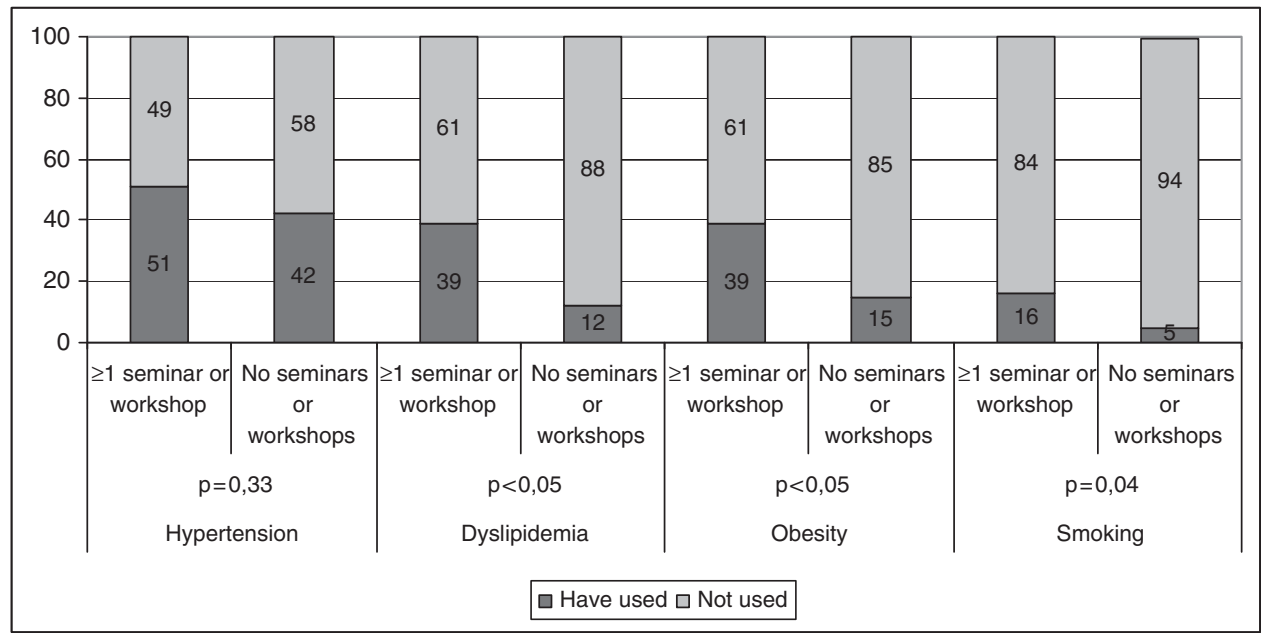

Figure 1 Reported use of guidelines and participation in training. Proportions (\%) of nurses who reported in 2006 $(n=127)$ have used the guideline during six months among those who reported have participated in at least one training session or in local workshop $(n=55)$ and among those who reported have not participated in training session or workshop $(n=77)$. 
Table 4 Attitudes towards clinical guidelines, proportions (\%) of nurses who had participated in VALTIT training and who had not participated in training, year 2006

\begin{tabular}{|c|c|c|c|c|c|c|c|}
\hline & \multicolumn{3}{|c|}{$\begin{array}{l}\text { Had participated in at least one } \\
\text { seminar or workshop }(n=50)\end{array}$} & \multicolumn{3}{|c|}{$\begin{array}{l}\text { Had not participated in any } \\
\text { seminars or workshops }(n=77)\end{array}$} & \multirow[t]{2}{*}{$P$-value } \\
\hline & Agree & Between & Don't agree & Agree & Between & Don't agree & \\
\hline $\begin{array}{l}\text { My occupational competence } \\
\text { is insufficient for adopting } \\
\text { the latest guidelines }\end{array}$ & 0 & 2 & 98 & 4 & 12 & 84 & 0.042 \\
\hline Guidelines are too complicated & 10 & 6 & 84 & 18 & 22 & 61 & 0.019 \\
\hline Guidelines are hard to find & 14 & 12 & 74 & 31 & 16 & 53 & 0.063 \\
\hline
\end{tabular}

Answering options were 'completely agree', 'partially agree', 'in between', 'partially disagree' and 'completely disagree'. First two options have been combined with 'agree' and the last two with 'don't agree'.

and dyslipidemia guidelines presenting medication as a major option of long-term treatment and second, behavioural change-oriented guidelines, the adult obesity and smoking cessation guidelines having lifestyle change as the central component of long-term treatment of these conditions.

This division was seen in the main items measuring familiarity with and use of guidelines and their changes. The hypertension guideline was the most familiar and the most often reported as used in clinical practice among physicians and nurses. This holds true for both before and after the educational intervention. Previous studies among Finnish health care professionals are in line with our results: the hypertension guideline has been well adopted into nurses' clinical practice (Alanen et al., 2008) and the best known guidelines among Finnish physicians are those on hypertension and dyslipidemia (Kuronen et al., 2006; Jousilahti et al., 2007).

Moreover, although there was an increase in nurses' familiarity with all the guidelines studied here; there was no increase in the use of the guidelines focussing on lifestyle change - a results that was somewhat disappointing. Among the physicians only the use of the adult obesity guideline increased.

Clinical guidelines typically focus on diagnostics and medical treatments, thus there is less research on guidelines focussing on behavioural change and its support. Among physicians, the activities of medical companies in providing training may further affect the use of the medication-centred guidelines. Furthermore, from the health care professionals' perspective, treating behavioural changes might be more challenging than providing pharmacotherapy, because of the lack of confidence in lifestyle counseling skills and because lifestyle change outcomes are not usually observed within a short period and relapses often occur (Brotons et al., 2005; Jallinoja et al., 2007). Interestingly, nurses read and use medicationoriented guidelines more often than behavioural change-oriented guidelines though their role is central particularly in lifestyle counseling. This may be due to a situation where treatment chains for obesity and smoking cessation have not been identified and resourced, and where there is no need or opportunities to apply these guidelines. Equally, a single cardiovascular risk factor, such as elevated cholesterol and blood pressure, can be seen as a disease requiring a quick reaction.

Previous studies have shown that organisational and leadership support is a central element in the implementation of evidence-based practices and guidelines (Michie et al., 2005; Gifford et al., 2006; Ploeg et al., 2007; Marchionni and Ritchie, 2008). As the proportion of those who reported have been recommended to use the guidelines increased, there might have occurred a shift to an atmosphere that is more favourable for guidelines. Moreover, among nurses the perception that one is incompetent to use the guidelines decreased. These changes are a good basis for the future guideline related programmes among nurses who traditionally have been less involved in evidence-based care and guideline use (Thompson et al., 2007; Goossens et al., 2008).

The primary care nurses' role is in transition as a whole and specifically in cardiovascular prevention in Finland and elsewhere, too (Buchan 
and Calman, 2004; Graham et al., 2007). Recently, it has been shown that a nurse-coordinated, preventive cardiology programme could improve the preventive care in routine clinical practice (Wood et al., 2008). Our study suggests that among nurses there is willingness to become acquainted with guidelines. Guidelines address items aimed at nurses, but the sufficient use of guidelines needs organisational support for multiprofessional collaboration (Sipila et al., 2008).

The effect of educational meetings on the health care practices has been, if any, small (Oxman et al., 1995; Grimshaw et al., 2004). In guideline implementation they can be seen as methods predisposing awareness to the item (Pathman et al., 1996). Combination of more active interventions, a multifaceted approach, should be tailored to suit local circumstances taking into account any particular potential barriers. When building implementative measures, one must consider the resources needed for successful implementation (http://www.sign.ac.uk/ guidelines/index.html). Beyond tailored approaches, organisational issues such as internal communication must be paid attention (Flottorp et al., 2003). When a guideline is adopted it can have an impact on clinical practices and the division of labour between nurses and physicians and thus promote the systematic support of health behaviour change (Alanen et al., 2008).

This was a live environment study and the major limitation of our study is that we did not have a control group. However, there were no other guideline implementation projects going on in the area during the study period. Although there might be a selection bias because participation in training was voluntary, we were able to compare nurses who had participated in guideline training and those who had not. The randomised controlled trial is recognised as the 'gold standard' in quantitative research, but in a real life setting an adequacy (rather than probability or plausibility) approach can be an acceptable method (Victora et al., 2004). The response rate was rather low among physicians. It might also be that those professionals who returned the questionnaire are those who are more interested in guidelines. Our results cannot in all respects be generalised to health care systems of other countries, but health care system of our area is typical for Finland and so generalisation in Finland is good.

\section{Conclusions}

Our results are encouraging with regard to familiarity with clinical guidelines. The results are partly disappointing with regard to use and suggest that a two-year intervention might not be enough to alter the deep-rooted practices and attitudes regarding lifestyle change related guidelines. The real challenge lies in the multiprofessional implementation of guidelines on cardiovascular risks with particular emphasis on lifestyle change as a treatment option.

\section{Acknowledgements}

The study has been funded by the Academy of Finland (grant no 25725250, Health Services Research programme) and Päijät-Häme Social and Health Care District, Finland.

\section{Competing interest}

The authors declare that they have no competing interest.

\section{Authors' contributions}

RK, PJ, RA and KP participated in the design and data collection of the study. RK performed the statistical analysis and drafted the manuscript. PJ, RA and KP helped to draft the manuscript. All the authors read and approved the final manuscript.

\section{References}

Alanen, S., Ijäs, J., Kaila, M., Mäkelä, M. and Välimäki, M. 2008: Hypertension guideline implementation: experiences of Finnish primary care nurses. Journal of Evaluation in Clinical Practice 14, 830-35.

Alanen, S., Johannala-Kemppainen, R., Jarja, J., Kaila, M., Klockars, M. and Mäkelä, M. 2007: Evaluation of current care effectiveness: a survey of hypertension guideline implementation in Finnish health centres. Scandinavian Journal of Primary Health Care 25, 232-36.

Brotons, C., Björkelund, C., Bulc, M., Ciurana, R., GodyckiCwirko, M., Jurgova, E., Kloppe, P., Lionis, C., Mierzecki, A., Piñeiro, R., Pullerits, L., Sammut, M.R., Sheehan, M., Tataradze, R., Thireos, E.A. and Vuchak, J. 2005: Prevention and health promotion in clinical practice: the 
views of general practitioners in Europe. Preventive Medicine 40, 595-601.

Buchan, J. and Calman, L. 2004: Skill-mix and policy change in the health workforce: nurses in advanced roles. $O E C D$ Health Working Papers. DELSA/ELSA/WD/HEA, vol. 8.

Elovainio, M., Eccles, M. and Mäkelä, M. 1999: Attitudes towards guidelines and a scale for measuring them. In Thorsen, T. and Mäkelä, M., editors. Changing professional practice. Theory and practice of clinical guidelines implementation. Copenhagen: DSI.

Flottorp, S., Håvelsrud, K. and Oxman, A.D. 2003: Process evaluation of a cluster randomised trial of tailored interventions to implement guidelines in primary care why is it so hard to change practice? Family Practice 20, 333-39.

Fogelholm, M., Valve, R., Absetz, P., Heinonen, H., Uutela, A., Patja, K., Karisto, A., Konttinen, R., Makela, T., Nissinen, A., Jallinoja, P., Nummela, O. and Talja, M. 2006: Rural-urban differences in health and health behaviour: a baseline description of a community health-promotion programme for the elderly. Scandinavian Journal of Public Health 34, 632-40.

Gifford, W., Davies, B., Edwards, N. and Graham, I. 2006: Leadership strategies to influence the use of clinical practice guidelines. Nursing Leadership (Toronto Ont) 19, 72-88.

Goossens, A., Bossuyt, P.M. and Haan, R.J.D. 2008: Physicians and nurses focus on different aspects of guidelines when deciding whether to adopt them: an application of conjoint analysis. Medical Decision Making 28, 138-45.

Graham, I., Atar, D., Borch-Johnsen, K., Boysen, G., Burell, G. and Cifkova, R. 2007: European guidelines on cardiovascular disease prevention in clinical practice: executive summary. Fourth Joint Task Force of the European Society of Cardiology and other societies on cardiovascular disease prevention in clinical practice (constituted by representatives of nine societies and by invited experts). European Journal of Cardiovascular Prevention and Rehabilitation 14 (Suppl 2), E1-40.

Grimshaw, J., Thomas, R., MacLennan, G., Fraser, C. and Ramsay, C. 2004: Effectiveness and efficiency of guideline dissemination and implementation strategies. Health Technology Assessment 8, 1-72.

Grol, R. and Buchan, H. 2006: Clinical guidelines: what can we do to increase their use? Medcal Journal of Australia 185, 301-302.

Jallinoja, P., Absetz, P., Kuronen, R., Nissinen, A., Talja, M., Uutela, A. and Patja, K. 2007: The dilemma of patient responsibility for lifestyle change: perceptions among primary care physicians and nurses. Scandinavian Journal of Primary Health Care 25, 244-49.

Jallinoja, P., Kuronen, R., Absetz, P. and Patja, K. 2006: Lääkehoidon, elintapahoidon ja ryhmäneuvonnan asema elintapasairauksien hoidossa - tutkimus lääkäreiden ja hoitajien näkemyksistä Päijät-Hämeessä [The role of pharmacotherapy, lifestyle modification and group

Primary Health Care Research \& Development 2010; 11: 241-249 counselling in treatment of lifestyle related diseases - a study on physicians' and nurses' attitudes in Päijät-Häme Province]. Suomen Laakarilehti 61, 3747-51.

Jousilahti, P., Komulainen, J., Hanski, T., Kaila, M. and Ketola, M. 2007: Perusterveydenhuollon lääkärit tuntevat hyvin Käypä hoito -suositukset [Knowledge of, attitudes to and use of current care guidelines among Finnish primary health care physicians]. Suomen Laakarilehti 62, 3319-23.

Kuronen, R., Jallinoja, P., Ilvesmäki, V. and Patja, K. 2006: Valtimotautiriskeihin liittyvät Käypä Hoito-suositukset: asenteet, tutustuminen ja käyttö Päijät-Hämeessä [Current Care Clinical Guidelines associated with the cardiovascular disease: familiarity, attitudes and use in the Päijät-Häme region, Finland]. Suomen Laakarilehti 61, 4571-77.

Marchionni, C. and Ritchie, J. 2008: Organisational factors that support the implementation of a nursing best practice guideline. Nursing Manager 16, 266-74.

Mazza, D. and Russell, S. 2001: Are GPs using clinical practice guidelines? Australian Family Physician 30, 817-21.

Michie, S., Johnston, M., Abraham, C., Lawton, R., Parker, D. and Walker, A. 2005: Making psychological theory useful for implementing evidence based practice: a consensus approach. Quality \& Safety in Health Care 14, 26-33.

Miilunpalo, S., Toropainen, E. and Moisio, P. 2001: Implementation of guidelines in primary health care. A challenge for the municipal health centres in Finland. Scandinavian Journal of Primary Health Care 19, 227-31.

Oxman, A., Thomson, M., Davis, D.A. and Haynes, B. 1995: No magic bullets: a systematic review of 102 trials of interventions to improve professional practice. Canadian Medical Association Journal 153, 1423-31.

Pathman, D., Konrad, T., Freed, G., Freeman, V. and Koch, G. 1996: The awareness-to-adherence model of the steps to clinical guideline compliance. The case of paediatric vaccine recommendations. Medcal Care 34, 873-89.

Peltonen, M., Korpi-Hyövälti, E., Oksa, H., Puolijoki, H., Saltevo, J., Vanhala, M., Saaristo, T., Saarikoski, L., Sundvall, J. and Tuomilehto, J. 2006: Lihavuuden, diabeteksen ja muiden glukoosiaineenvaihdunnan häiriöiden esiintyvyys suomalaisessa aikuisväestössä [Prevalence of obesity, type 2 diabetes, and other disturbances in glucose metabolism in Finland - the FIN-D2D survey]. Suomen Laakarilehti 61, 163-70.

Ploeg, J., Davies, B., Edwards, N., Gifford, W. and Miller, P. 2007: Factors influencing best-practice guideline implementation: lessons learned from administrators, nursing staff, and project leaders. Worldviews on Evidence-based Nursing 4, 210-19.

Sipila, R., Ketola, E., Tala, T. and Kumpusalo, E. 2008: Facilitating as a guidelines implementation tool to target resources for high-risk patients - The Helsinki Prevention Programme (HPP). Journal of Interprofessional Care 22, 31-44.

Thomas, L., Cullum, N., McColl, E., Rousseau, N., Soutter, J., and Steen, N. 2000. Guidelines in professions allied to medicine. Cochrane Database of Systematic Reviews, vol. 2. 
Thompson, D., Estabrooks, C., Scott-Findlay, S., Moore, K. and Wallin, L. 2007: Interventions aimed at increasing research use in nursing: a systematic review. Implementation Science 2, 1.

Victora, C., Habicht, J. and Bryce, J. 2004: Evidence-based public health: moving beyond randomised trials. American Journal of Public Health 94, 400-405.
Wood, D., Kotseva, K., Connolly, S., Jennings, C., all A.M.E. and EUROACTION Study Group. 2008: Nursecoordinated multidisciplinary, family-based cardiovascular disease prevention programme (EUROACTION) for patients with coronary heart disease and asymptomatic individuals at high risk of cardiovascular disease: a paired, cluster-randomised controlled trial. Lancet 14, 1999-2012. 